\title{
O PATRIMÔNIO INDUSTRIAL DE PRESIDENTE PRUDENTE DIANTE DA ESPECULAÇÃO IMOBILIÁRIA
}

Dayane Tieme Yamada Carrenho' (e-mail:), Lucas Augusto Blaia da Silva ${ }^{1}$ (e-mail:), Fabrícia Dias Da Cunha De Moraes Fernandes Borges ${ }^{2}$ (e-mail:).

Universidade do Oeste Paulista - UNOESTE, Faculdade de Engenharias e Arquitetura e Urbanismo, Presidente Prudente, SP. E-mail: dayaneyamada@yahoo.com.br, lucas blaia@hotmail.com, fabricia.arquiteta@gmail.com.

\section{RESUMO}

Este artigo frisa a importância e o legado do patrimônio industrial para a cidade de Presidente Prudente-SP, a partir das edificações que surgiram ao longo da implantação da linha férrea, no qual acarretou um capítulo importante para o desenvolvimento urbano e econômico da cidade. 0 estudo ainda permite demonstrar através de duas edificações históricas e de suma relevância para o contexto histórico e cultural da cidade, o processo de degradação, mutilação e destruição que vem ocorrendo em importantes patrimônios pela cidade, como o caso da Sanbra Sociedade Algodoeira do Nordeste Brasileiro - SANBRA (de 1938) que teve grande parte levada a baixo, e a antiga fábrica de bebidas Funada (de 1947) totalmente destruída, ambas vítimas da ociosidade somadas a especulação imobiliária. Fenômeno este que vem assolando e passando por cima do patrimônio, da história e da memória da sociedade.

Palavras-chave: Patrimônio Industrial, Presidente Prudente, Bebidas Funada, Sanbra, Especulação imobiliária.

\section{THE INDUSTRIAL PATRIMONY OF PRUDENT PRESIDENT IN VIEW OF THE REAL ESTATE SPECULATION}

\begin{abstract}
This article presents the importance and legacy of the industrial heritage of the city of Presidente Prudente-SP, from buildings that have arisen along the railway line implementation, which led to an important chapter for urban and economic development of the city. The study also allows to demonstrate through two historic buildings and of great relevance to the historical and cultural context of the city, the process of degradation, mutilation and destruction that has taken place in important heritage sites in the city, as the case of Sociedade Algodoeira do Nordeste Brasileiro SANBRA (1938) which hard a large part of it's original building taken down, and the old factory Bebidas Funada (1947) totally destroyed, both victims of idleness added with real estate speculation. This phenomenon is raging and going over the heritage, history and memory of society.

Keywords: Industrial Heritage, Presidente Prudente, Bebidas Funada, Sanbra, Real State Speculation.
\end{abstract}




\section{INTRODUÇÃO.}

O patrimônio industrial da cidade de Presidente Prudente, interior do estado de São Paulo, no qual tem laços fortemente amarrados com a história e desenvolvimento urbano e econômico da cidade. Cidade esta que de acordo com Honda (2011) teve seu desenvolvimento urbano e industrial ao longo da linha férrea instalada na cidade no inicio do século XX e que será discutida ao longo deste trabalho. Com a chegada da linha férrea, houve uma tendência muito forte de assentamentos de industrias próxima a ela, "Essas construções constituem testemunhos significativos da arquitetura industrial ferroviária, [...] como afirma a Carta de Veneza, porque ela, com o passar do tempo, construíram-se importantes componentes para a construção da cidade" (FIORIN. HIRAO apud KUHL, 2009).

Com isso, é importante ressaltar a importância de tais edificações, como patrimônios e sua significância para cidade e discutir o que vem acontecendo ao longo dos anos com a especulação imobiliária, na cidade de Presidente Prudente. "Há muito a preservação patrimonial afastou-se de um caráter nostálgico ou saudosista, [...] Já as construtoras enxergam estas áreas como "de oportunidade". (MENEGUELLO, 2011)

Com base nisso, duas das indústrias que impulsionaram o crescimento urbano e econômico do município de Presidente Prudente, como: o antigo edifício da Bebidas Funada, que foi totalmente destruído dando lugar a uma torre residencial e comercial, e a SANBRA (Sociedade Algodoeira do Nordeste Brasileiro), que sofreu uma "mutilação" física, transformando parte do seu sítio industrial em um grande condomínio habitacional, apenas preservando sua chaminé, a termoelétrica e casa da máquina. Estes preservado por órgãos de proteção ao patrimônio, vêm sendo degradado, que no qual que está em processo de ruínas, por conta do seu abandono e falta de interesse, tanto para o setor público, como para o privado, servindo como abrigo para moradores de rua, marginalização e outros afins ilícitos.

Rufinoni (2013) abre caminhos de forma crítica, do momento atual sobre preservar um edifício histórico industrial, considerado como bem cultural significativo do seu local, da cidade e para seus habitantes, nisso, a consequência comum da não preservação, um dos problemas "se deve à grande extensão de área ocupadas, ao fato de geralmente se localizarem em regiões estratégicas de grandes cidades e ao considerável baixo custo dos terrenos". (RUFINONI, 2013, p. 219). Ainda para tal autora (2013), entende-se que, as identificações desses edifícios são consideradas como monumentos coletivos portadores de valores e especificidades que compõem paisagens únicas, e que geralmente não comparecem na elaboração de projetos de intervenção.

A discussão desta pesquisa não frisa apenas na questão do patrimônio industrial prudentino, como também, vem elencar o que têm acontecido na cidade com o agente da especulação somado a ociosidade, e descaso de tais edificações, que aos poucos vemos que não só são degradadas, mutiladas, desta forma, desaparecendo na paisagem urbana, como também vemos a nossa história se esmaecendo diante de nós.

\section{METODOLOGIA}

A metodologia empregada é composta de levantamento bibliográfico, pesquisa documental, adjunto a leituras físicas in loco, nas áreas de estudo abordadas. A pesquisa documental ajudou a compor fatos históricos para que fosse confeccionar um material condizente para ser discutidos e delongados neste trabalho, já o levantamento bibliográfico permitiu direcionar, identificando e relacionando os fatores que integram o processo de discussão em pauta e tanto em relação a questões relativas a arquitetura patrimonial, e sua magnitude. 
Adjunto a leituras e observações realizadas in loco, para melhor compreender os processos de transformação na paisagem urbana.

\section{PATRIMÔNIO INDUSTRIAL PRUDENTINO}

Segundo Honda (2011) a ocupação ou colonização é recente na região do município de Presidente Prudente-SP, tudo aconteceu por volta de 1850, relacionado a dois momentos distintos: "a frente de expansão e a frente pioneira", ou seja, a primeira frente se refere aos posseiros "para substência e troca", (HONDA, 2011, p. 85) já a frente pioneira se refere como empreendimento econômico. A cidade surgiu a partir de vários contextos históricos ocupacionais das terras da alta sorocabana, no qual, foi um resultado da divisão de terras e da atuação de dois fundadores: Caronel Goulart e Caronel Marcondes.

Através do crescimento econômico e rural e com "a vinda da Estrada de Ferro acentuou a tal divisão, surgindo então duas primeiras vilas que receberiam o nome de seus fundadores: Vila Goulart, que posteriormente viria se tornar o centro prudentino, e a Vila Marcondes" (MENDONÇA; COSTA, 2014, p. 2). Para Fiorin e Hirao (2015), foi a partir da integração desses dois núcleos, em volta da ferrovia, que surgiu a cidade de Presidente Prudente, que inclusive era o nome da estação de trem.

Fiorin e Hirao (2015) afirmam que a linha férrea, foi o principal elemento da formação do núcleo, responsável pelo surgimento das áreas industriais, vale ressaltar que em 1925 houve uma lei que proibia a instalação de máquinas ou indústrias exatamente nos acessos principais das antigas estações de trem, desta determinou-se que as fábricas ficassem, do outro lado da linha, portando, na vila Marcondes. As indústrias foram locadas no entorno da linha férrea, favorecendo o escoamento de matéria prima e produto fabricado, entre outras cidades e estado. Fiorin e Hirao afirmam, exceto o "Matadouro, construído em 1929, que se encontrava totalmente afastado da área urbana, próximo o córrego do veado, e o Cortume Crespoldi, ambas as atividades dependentes de cursos d'água para seu funcionamento". (FIORIN; HIRAO, 2015, p. 43).

Algumas delas citadas acima não existem mais, porém há alguns remanescentes na cidade, onde "constituem a paisagem urbana do antigo núcleo urbano da cidade, e nos ajudam a entender e ilustram o início da história prudentina". (MENDONÇA; COSTA apud SOUSA, 2008, p.16). Desta forma, a seguir será apresentado relato descritivo da situação de alguns desses espaços considerados patrimônio, que passaram por inúmeras transformações. Assim teremos um melhor entendimento da importância da preservação desses edifícios em relação ao desenvolvimento da cidade de Presidente Prudente.

\section{SANBRA - SOCIEDADE ALGODOEIRA DO NORDESTE BRASILEIRO}

A antiga indústria, Sociedade do Nordeste Brasileiro (SANBRA), de acordo com Fiorin e Hirao (2015), foi inserida e inaugurada por volta de 1948 na Fazenda São José em Presidente Prudente, nas margens da linha férrea Sorocabana (ao lado oposto, no sentido Vila Marcondes), na época resultando em uma melhor estratégia de recebimento de matéria prima e escoamento de produto acabado, com isso, as terras possuíam " $62.882 \mathrm{~m}^{2}$ formalizadas através de duas matrículas de imóveis", o objetivo principal da empresa era atingir o mercado de algodão, sementes oleaginosas e cereais em geral e que posteriormente virou uma usina, por produzir sua própria energia. Atualmente, após mudanças na malha urbana da cidade, a SANBRA faz parte de dois bairros: Vila Furquim e Vila Maristela, com ambos acessos.

Segundo o jornal Ifronteira (2013), após a década de 1960, com o declínio na produção agrícola, houve o emulsionamento do fechamento das indústrias em Presidente Prudente, como foi o caso da SANBRA e entre outras. Onde também, Fiorin e Hirao (2015), ressaltam que após o fim das atividades comerciais da estação e da linha férrea, tanto para passageiros como de cargas, 
com o passar do tempo estes edifícios foram perdendo sua potencialidade, o que acarretou o abandono, degradações, descaracterizações e demolições.

Para Mendonça e Costa (2013) as características gerais da indústria SANBRA, como inúmeras outras fábricas, principalmente na margem da linha férrea, "apresentou uma relativa despreocupação estética, por visar mais a função e não a forma", foi projetado principalmente para atender as necessidades da indústria, sendo construído de uma forma que ocupasse todo o terreno.

Parte do complexo industrial SANBRA foi vendido para uma construtora de conjuntos habitacionais, onde Fiorin e Hirao (2015) ainda salientam que através de esforços do Ministério Público do Estado de São Paulo, preservou-se: o galpão da termoelétrica, uma pequena construção, que provavelmente servia como apoio e a torre, tornando-se um símbolo significativo do período. Segundo os mesmos autores (2015) o Ministério Público "abriu um inquérito para preservação desta edificação, justificando como patrimônio histórico e aos docentes que participaram do Grupo de Pesquisa Projeto, Arquitetura e Cidade da FCT-Unesp [...] emitidos pareceres técnico para justificar". (FIORIN; HIRAO, 2015, p. 55)
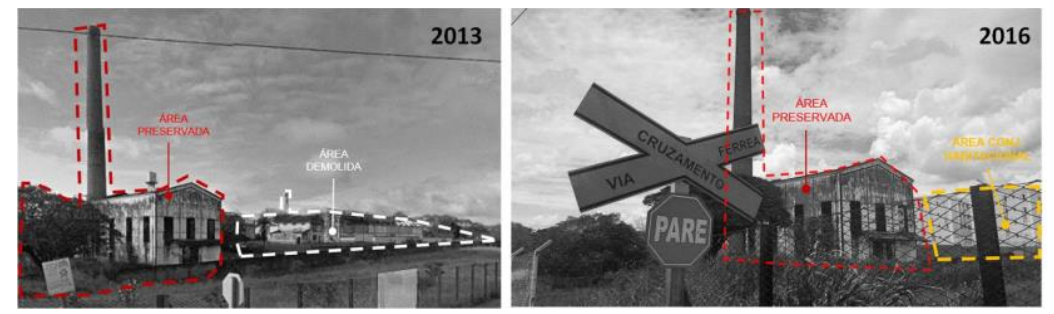

Figura 02. Edificio SANBRA antes da demolição e depois, após construção dos novos edifícios.

Fonte: Maps com acesso em 2016, esquematizado pelos autores, e arquivo pessoal esquematizado também pelos autores.

Podemos observar que, "tal despreocupação com a historicidade do que deveria ser considerado patrimônio industrial para o município, resultou num processo especulativo", contudo, aproveitaram a "oportunidade" do local estar em desuso, "sendo utilizadas para atividades consideradas ilícitas e em ruínas", para dar a contrapartida na mídia, para então justificar o incomodo que a população supostamente tinha no entorno.

Para Rufinoni (2013) "reconhecimento dessas especificidades e a garantia de sua salvaguarda, conforme recomendam os documentos internacionais analisados, no entanto, são ações que enfrentam diversas dificuldades práticas", ou seja, indústrias que muitas vezes ocupam área de grandes parcelas de terreno urbano, resultando nos principais entraves para a sua efetiva preservação. "Além das dificuldades relacionadas ao entendimento das particularidades compositivas desse patrimônio, essas extensas áreas são muito cobiçadas pelo mercado imobiliário, que dificulta sobremaneira qualquer ação de preservação". (RUFINIONI, 2013, p. 193)

Vale ressaltar que, os edifícios e os galpões demolidos realmente faziam parte das atividades fabril, são parcelas que foram jogadas no "lixo", no qual efetivamente faziam parte na montagem e do produto acabado, abrigando máquinas e operários, e o que foi preservado, era, no entanto, a usina (termoelétrica, e chaminé), eram destinadas a gerar energia para o todo complexo industrial da SANBRA.

\section{INDÚSTRIA E COMÉRCIO DE BEBIDAS FUNADA.}

A história da Bebidas Funada, parte da história dos seus fundadores no qual se assemelha com a de muitos imigrantes que chegaram ao Brasil no início do século $\mathrm{XX}$, em busca de uma oportunidade. Em 1931, o Sr. Mampei Funada junto a sua esposa Kimi Funada, partiu do Japão rumo ao Brasil, com seus quatro filhos. (SOUSA, 2008, p. 12). 
Chegando aqui, foram trabalhar como colonos em uma fazenda chamada Santo Antonio, no município de São José do Rio Pardo, alguns anos após terem arrendado terras na cidade de Martinópolis, a família adquiriu terras em Caiabu, também na região interior paulista. Em 1942 os Funada migraram das atividades rurais para a cidade de Presidente Prudente-SP, onde abriram um modesto comércio localizado na rua Rui Barbosa, esquina com a Av. Cel. José Soares Marcondes, importante ponto de localização que era sorveteria e bar e foi a partir de então que a que o Sr. Mampei investiu na fabricação de refrigerantes, fundando em 1947, a Funada e Filhos. (SOUSA, 2008, p. 12).

A fábrica, localizada na rua XV de Novembro, esquina com a rua Barão do Rio Branco, era mais afastada do quadrilátero central, porém ainda continuava muito próximo a ele. $O$ prédio, era constituído de um pequeno sobrado voltado para a parte administrativa, um galpão para a produção de bebida e depósito. Onde Sousa (2008) relata que a capacidade de produção da fábrica chegava a de 150 garrafas por hora, produzindo desde guaraná, soda limonada, água tônica, vinagre entre outros. Já em 1952, a fábrica foi renomeada para "Indústria e Comércio de Bebidas Funada Ltda" se especializando na produção de refrigerantes (guaraná, soda limonada, laranjada "Mican" e a tão tradicional tubaína, fabricando cerca de 800 garras/hora, graças à tecnologia que aos poucos foi sendo investida, na década de 60 , a produção já passava de 3.500 garrafa/hora, em 1970 a indústria, foi considerada como "Indústria do ano", iniciando o processo de exportação para países da América do sul, desde então a fábrica e seus produtos tornaram-se símbolos de identidade para a cidade de Presidente Prudente.

Já na década de 1980, a fim de atender as demandas de alta produção as instalações da antiga fábrica foram deixadas, passando para um grande terreno de $48.000 \mathrm{~m}^{2}$ em uma área mais afastada do centro da cidade Funada (SOUSA, 2008, p. 12). De lá para cá a edificação da antiga fábrica ficou ociosa, gerando abandono, e sendo alvo de vandalismos e abrigo para uso de drogas ilícitas, assim como a edificação da SANBRA.]

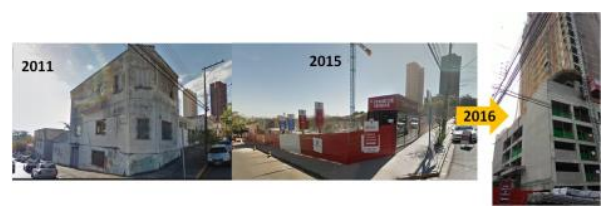

Figura 03. Imagem antiga fábrica de bebidas e atualmente.

Fonte: Maps (2015) acesso em 10 de agosto de 2016; e esquematizada pelos autores (2016).

Aproveitando a localização privilegiada, somada a ociosidade do local, e incomodo da população, uma incorporadora da cidade assumiu o lote em 2014, destruindo totalmente a preexistência presente, ignorando a memória, a história e a significância para a cidade e respectivamente a paisagem urbana. A preexistência foi destruída, para dar lugar a uma nova torre comercial e residencial com mais de 15 pavimentos, transformando totalmente a paisagem urbana local. O processo de especulação imobiliária, em especial em cima do patrimônio industrial nas cidades para Meneguello (2011) é uma constante ameaça para galpões e antigas fábricas, o que os torna alvo de um processo constante de destruição da memória industrial nas cidades do Brasil.

\section{PATRIMÔNIO INDUSTRIAL X ESPECULAÇÃO IMOBILIÁRIA.}

Quando os sítios ou edifícios em pauta são de origem industrial, Rufinoni (2013) ressalta que o distanciamento entre teoria e prática no tratamento desse patrimônio específico assume proporções maiores. Contudo, a evidência no tratamento desses bens culturais, concentra-se fragilidade dos preceitos da interpretação da teoria do restauro, "ficam ainda mais evidentes, sobretudo devido às dificuldades relacionados com a valorização desses artefatos [...] ou ainda devido às fortes pressões especulativas de diferentes naturezas. " (RUFINONI, 2013, p. 244) 
Meneguello (2011) ainda observa que enquanto outros países europeus e latinoamericanos este patrimônio tem sido preservado e requalificado em usos práticos muito diversos e não apenas em museus-, enquanto aqui há ainda uma carência em olhar para essas edificações e reconhecer os valores tanto na vertente histórica, quanto social, arquitetônica, turística, artística e econômica. A autora (2011) ainda observa que faltam políticas nacionais e locais voltadas para a preservação do patrimônio industrial no país, onde conclui que: "O desmantelamento dos espaços, seja pela falta de critérios de valorização por parte dos órgãos oficiais, seja pela força da especulação imobiliária que foca sua atenção nestas rentáveis áreas hoje centrais, faz do patrimônio industrial um problema urbano em larga escala" (MENEGUELLO, 2011).

\section{CONCLUSÃO}

Como já discorrido anteriormente, o patrimônio industrial nas cidades é um importante integrante da história de uma cidade, e consequentemente para a memória e cultura da sociedade. No Brasil, ainda é difícil verificar a valorização do patrimônio industrial como um agente atuante que impulsiona a educação, cultura, o turismo e economia, seja devido à falta de políticas públicas locais e nacionais, somada ao abandono e o grande oponente (e de peso): a especulação imobiliária.

No caso de Presidente Prudente, interior do estado de São Paulo, não tem sido diferente do que vem ocorrendo nas demais cidades do país, a cidade teve seu crescimento urbano e econômico graças as indústrias instaladas até a metade do século $X X$, nas quais muitas das edificações estão sendo degradadas e deixadas ao relento, e que quando são lembradas é para algum fim lucrativo, totalmente inerte ao desprendimento da memória, e valor histórico dos seus. Onde incorporadoras tem arrematado tais patrimônios degrando-os e ou totalmente destruindoos para dar lugar a altas torres modernas, fazendo uso das localizações privilegiadas em que se encontram, e ignorando totalmente a paisagem e contexto urbano onde se estão inseridas, como foram citados e delongados neste artigo com a SANBRA e a antiga fábrica de Bebidas Funada.

Com este artigo, cabe a reflexão e um balanço do legado patrimonial industrial prudentino, sua importância histórica para a cidade, e o que vêm acontecendo ao longo dos últimos anos, onde o valor especulativo vêm dando lugar a valor memorável, histórico e social.

\section{REFERÊNCIAS}

FIORIN, E; HIRAO, H. Cidades do interior paulista: Patrimônio urbano e arquitetônico. 1. ed. São Paulo: Paco Editorial, 2015.

HONDA. S. Habitação de baixa renda como produto do capital: o programa de arrendamento residencial (PAR) em Presidente.

IFRONTEIRA. Justiça decide por conservação de chaminé e galpões da Sanbra. Fev, 2014. Disponível em: http://g1.globo.com/sp/presidente-prudente-regiao/noticia/2014/02/justicadecide-por-conservacao-de-chamine-e-galpoes-da-sanbra.html>. Acesso em: 21 abr. 2016.

Kühl, B. Preservação do Patrimônio Arquitetônico da Industrialização: Problemas teóricos de restauro. Cotia, SP: Estação.

MENDONÇA, D; COSTA, R. Importância e preservação do legado industrial: O caso do eixo industrial em Presidente Prudente/SP. Paisagem Cultural, Patrimônio e Projeto. Belo Horizonte, set. 2014.2 Disponível em: <http://www.forumpatrimonio.com.br/paisagem2014/trabalho/376/importancia-e-preservacao- 
do-legado-industrial-o-caso-do-eixo-industrial-em-presidente-prudentesp>. Acesso em: 10 mai. 2016.

MENEGUELLO, C. Análise antigas fábricas de São Paulo: o valor do patrimônio ainda é substimado. Folha de São Paulo, São Paulo, 23 de jan. 2011. Disponível em: < http://www1.folha.uol.com.br/fsp/cotidian/ff2301201102.htm>. Acesso em: 11 ago. 2016.

RUFINONI, M. Preservação e Restauro Urbano: intervenções em sítios históricos industriais. 1. ed. São Paulo: Editora FAP - UNiFESP; EDUSP - Editora da Universidade de São Paulo, 2013.

SANTOS, W. Diagnóstico histórico e econômico da região de Presidente Prudente. Presidente Prudente: Waldery Santos/Jornalismo e pesquisa de história, 1999. 171 p.

SOUSA, A. As origens do capital industrial nipo-brasileiro no munícipio de Presidente Prudente. Faculdade Integradas Antônio Eufrásio de Toledo - TOLEDO, Presidente Prudente, 2008. Disponível em: < http://intertemas.unitoledo.br/revista/index.php/Juridica/article/viewFile/120/123>. Acesso em: 13 ago. 2016. 